\title{
Relationship between Type of White Matter Tract Affection and Pathological Grade of Pediatric Brain Tumour Assessed by MR Diffusion Tensor Imaging and Fiber Tractography
}

\author{
SAMIA Y. HEIKAL, M.Sc.*; IMAN M. ZAKY, M.D.*; MOHAMED A. EL-BELTAGY, M.D.** and \\ AYMAN ABD EL-HAMID EL-BASMY, M.D.*** \\ The Department of Radio-Diagnosis, National Cancer Institute*, The Departments of Radiology** and Neurosurgery***, \\ Faculty of Medicine, Cairo University
}

\begin{abstract}
Background: Incorporation of WM fibers within a tumor mass, seen especially in low-grade tumors, and destruction of WM fibers by high-grade tumors can be depicted by MR diffusion tensor imaging and fiber tractography. These features have profound implications for the extent of resection amenable for the individual tumor.
\end{abstract}

Aim of Study: The purpose of this study is to evaluate the role of MR diffusion tensor imaging and fiber tractography in accurately depicting the relation between the grade and aggressivity of the paediatric brain tumour and the pattern of affection of white matter tracts in their direct vicinity. These information help the neurosurgeons to take a decision about the extent of excision and safety margin around the tumour.

Material and Methods: A total of fifty patients with brain tumors were included in this study using pre-operative contrastenhanced magnetic resonance imaging and DTI fiber tractography for preoperative depiction of the relation between white matter tract affection and aggressivity of the tumour.

Diffusion tensor imaging, by improving the recognition and characterization of white matter tracts, offers a glimpse into the brain microstructure at a scale that is not easily accessible with other modalities.

Result: The extent of white matter pathway involvement was clearly identified in all patients by using color-coded DT imaging maps and MR Tractography and was correlated with the pathological grade of the tumour.

Pattern I (not affected) is a rare pattern exclusively found in benign acting tumours. It was seen within 4 cases $(17.4 \%)$ of the benign acting group only.

Pattern II (displacement) is the most common pattern being detected in 19 cases $(82.6 \%)$ of the benign acting group and in 15 cases $(68.2 \%)$ of the malignant acting group.

Pattern III (oedematous) is the second most common type of tract involvement seen within 2 cases $(8.7 \%)$ of the benign acting group and within 9 cases $(40.9 \%)$ of the malignant acting group.

Correspondence to: Dr. Samia Y. Heikal, The Department of Radio-Diagnosis, National Cancer Institute, Cairo University
Pattern IV (infiltrated and partially disrupted) was seen within 2 cases $(8.7 \%)$ of the benign acting group and within 7 cases $(31.2 \%)$ of the malignant acting group.

Pattern V (destroyed) was detected in 3 cases $(13.6 \%)$ of the malignant group and no cases in the benign acting group.

Conclusion: Diffusion-tensor imaging allowed for the detailed visualization of WM tract affection by the tumour. The most common pattern of affection detected in our study is the displacement pattern with prevalence in the benign acting group of tumours. Destruction pattern was totally confined to the malignant acting lesions. Edema pattern and partial disruption pattern are more prevalent in the malignant acting lesions. Despite some limitations and pitfalls, DTI is currently the only clinically feasible method of demonstrating the white matter tracts in vivo.

Key Words: Diffusion tensor imaging (DTI) - Brain tumor Magnetic resonance image - Tractography White matter tracts.

\section{Introduction}

SURGICAL excision of brain tumors remains a big challenge especially in pediatric population. Brain tissue is delicate and vital and unlike most of human tissues, it does not regenerate. As all brain tissue is of crucial importance, there's no "safety margins" in brain tumor surgery. The neurosurgeon often finds himself in the dilemma of maximal excision versus maximal safety and reduction of post surgical morbidity caused by affecting eloquent areas in the brain. The most identifiable eloquent areas are the motor and sensory cortex, as well as their corticospinal and associated projections [1].

Improvement of the patient's outcome is primarily dependent on the preservation of cortical as well as subcortical function [2]. 
MR tractography (Diffusion Tensor Imaging (DTI)-Fiber Tractography) represents a noninvasive technique for assessing White Matter (WM) tract integrity contiguous to the lesions before and after surgery providing prognostic data [1]

DTI-FT data can also be intraoperatively integrated into frameless stereotactic neuro-navigational systems so that the neurosurgeon can appreciate the proposed location of significant tracts or eloquent brain areas $[\mathbf{1 , 4 , 5}$.

Localizing the corticospinal tracts is especially critical in children because their white matter is maturing and, hence, is highly vulnerable to insult [5].

DTI parameters derive from the detection in vivo of the direction and the magnitude of water diffusion in biological tissues. The measurement of anisotropic diffusion of water molecules is calculated as the Fractional Anisotropy (FA) and represents a quantitative measure of WM microstructural integrity. A second parameter, which can be measured, is the Apparent Diffusion Coefficient (ADC) which evaluates the overall magnitude of diffusion of water in tissue [3].

The pattern of white matter affection is strongly influenced by the pathological grade of tumour.

Aim of study:

The purpose of this study is to evaluate the role of MR diffusion tensor imaging and fiber tractography in accurate depiction of white matter tract affection patterns in view of the pathological grade of the brain tumour.

\section{Material and Methods}

This paper is adapted from the thesis submitted by the first author to the Faculty of Medicine, Cairo University, in partial fulfillment of the MD degree in Diagnostic Radiology. The work was a prospective study conducted on 50 pediatric patients (26 male and 24 female), age range 1-16 years; mean age 7 , with different types of brain tumors before undergoing surgery.

It was conducted at the Children's Cancer Hospital Medical Imaging Department in Cairo (57357) between June 2015 and April 2017.

Inclusion criteria included pediatric patients with brain tumours in their initial presentation. We including only primary lesions (except for one case of a single cerebral metastasis). Exclusion criteria included patients who received treatment before surgery, MRI contraindications or vitally unstable patients.

The study's protocol was approved by the Research Ethics Committee, Faculty of Medicine, Cairo University. Patients consents were unnesseccary as the DTI study was part of the MRI protocol for pre-operative brain tumours.

The most common diagnosis were gliomas with their different grades. According to the 2016 WHO grading system [6], the given pathologies are classified into four grades with each increasing grade implying lesser degrees of differentiation, increasing anaplasia, increasing proliferative potential, and mitotic activity Fig. (1).

Grade I: Included 20 patients constituting 40\% of cases including DNT (dysembryoblastic neuroepithelial tumours), craniopharyngomas, pilocytic astrocytomas, ganglioma and another low grade glioma.

Grade II: Included 3 patients constituting 6\% of cases including PXA (pleomorphic xanthoastrocytoma) and germinoma.

Grade III: Included 10 cases constituting 20\% of cases including anaplastic astrocytomas, anaplastic epyndymomas, atypical neurocytoma and atypical pituitary adenoma.

Grade IV: Included 12 cases constituting 24\% of cases included medulloblastomas, glioblastomas multiforme, ATRT (Atypical Teratoid Rhabdoid tumour) and metastatic osteosarcoma.

The pathology of five patients was not yet available at time of the study constituting $10 \%$ of cases.

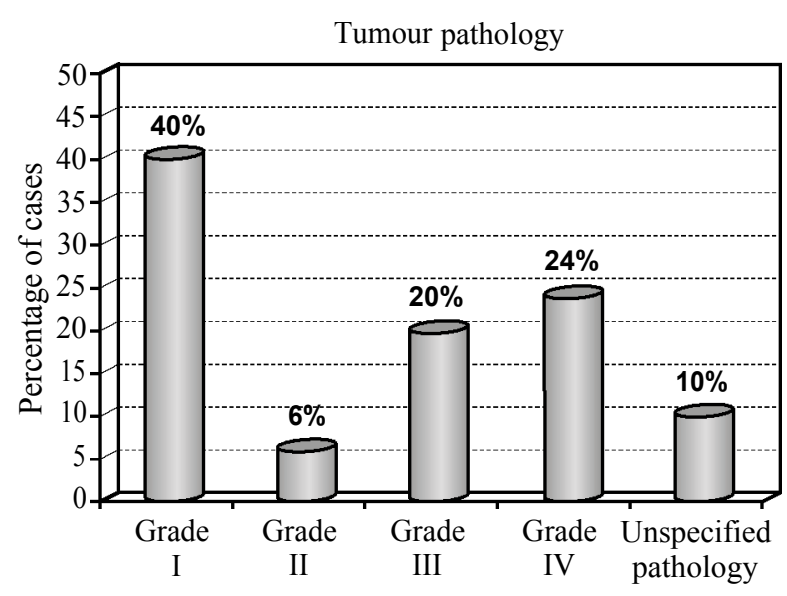

Fig. (1): Tumour classification included in our study. 

to:

Each patient included in the study was subjected

Full history taking:

The majority of the studied cases were in the age range of 3-6 years (preschool age) with a slight majority of males over females. Males represented 26 patients $(52 \%)$ and females represented 24 patients $(48 \%)$.

Thorough clinical examination including general and detailed neurological examination.

\section{Magnetic resonance imaging protocol:}

MR examination technique was performed using a 3T Philips Ingenia scanner (Philips, Best, The Netherlands), software version 4. A multichannel head coil was used for the reception of MR signal.

Diffusion Tensor Imaging (DTI) data were obtained using single-shot spin echo, echo planar imaging sequence (TR/TE $8750 / 100 \mathrm{~ms}$ ) with parallel imaging (SENSitivity Encoding [SENSE] reduction factor of 2 ). Diffusion gradients were applied along 32 axes, using a $b$-value of 0 and $800 \mathrm{~s} / \mathrm{mm}^{2}$.

An acquisition data matrix of $112 \times 112$ was used, leading to voxel dimensions of $(2.5 \times 2.5 \mathrm{X}$ $3 \mathrm{~mm}^{3}$ ). FOV (field of vision) varied according to the patient's head size. Slices were acquired in the axial plane in a regular ascending order with a thickness of $3 \mathrm{~mm}$ and no gap. A 3D T1-weighted image set ( $T 1$ W-3D FFE (Fast Field Echo), resolution 1 X 1 X 1 mm ) was acquired for anatomical localization. This was followed by axial 2D T2, T2 FLAIR and postcontrast T1 WIs for tumor characterization.

\section{Diffusion tensor imaging tractography:}

Image preprocessing and Fiber Tractography: The DTI and 3D T1 FFE images were transferred to the offline workstation (Philips View forum Extended MR Workspace Version 3.2) where the DTI images undergo linear registration using the diffusion registration tool, to overcome the effect of Eddy currents and head motion on the diffusion data. Registered images are opened in the MR Diffusion application for production of parameteric maps (FA, FA color maps, ADC \& DWI trace). Registered diffusion tensor images were then loaded into the Fibertracking application, and the 3D T1 TFE images were used as the anatomical underlay for better localization of seed placement locations, color coded FA maps were viewed with anatomical images underneath giving both anatomical infor-

mation and information about fiber orientation. Fig. (2): Tumour behaviour (benign or malignant acting).
The direction and anatomy of the tracts are seen in the directionally encoded FA maps, where a specific color is assigned to tracts running in the three orthogonal planes: Red is for right to left tracts, green for anteroposterior tracts, and blue for craniocaudal tracts. A 3D display of tracts was created. For creating 3D fiber tracts, inclusionary ROIs (or seeds) was drawn (placed) along the course of the tract in the (axial, sagittal or coronal) color encoded FA map in single or consecutive sections, while exclusionary ROIs were drawn on the spurious fibers that needed to be excluded from a specific fiber bundle. The software then automatically traces the assigned tract and presents it in a 3D manner. Regions of Interest (ROIs) were drawn within identifiable WM tracts affected by tumor, avoiding grossly cystic and necrotic regions, known fiber crossings, and gray matter. The following images were produced from the Fibertracking application: (1): FA maps. (2): Directionallyencoded color FA maps. (3): 2D fiber Tractography maps. (4) 3D fiber Tractography maps.

Color-coded DTI maps were analyzed, followed by tractography of individual tracts. The location of each tract and its hue on directional color maps were classified as normal or abnormal, based on comparison to the homologous tracts in the contralateral hemisphere, which were unaffected by tumor.

\section{Results}

The population enrolled in this study compromises 50 patients, $26(52 \%)$ were males and 24 $(48 \%)$ were females. Their age ranged from 1 to 16 years with a mean age of 7 .

We classified the tumors encountered in the study into two main groups, benign acting and malignant acting Fig. (2).

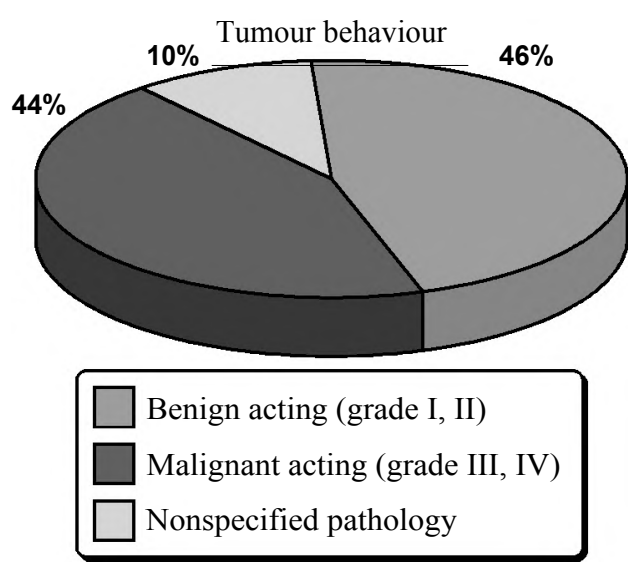


1- Benign acting (grade I and II lesions) compromised 23 patients.

2- Malignant acting (grade III and IV lesions) compromised 22 patient.

The extent of white matter pathway involvement was clearly identified in all patients by using colorcoded DT imaging maps and MR Tractography. Normal white matter pathways demonstrated on DT imaging appeared in the unaffected contra lateral hemisphere cases.

We adopted the following criteria for tract involvement patterns:

Pattern I (not affected): Fibers are in the correct anatomical location, characterized by normal FA and normal ADC similar to the homologous tract in contralateral hemisphere.

Pattern II (displacement): Was characterized by normal or mildly decreased FA and normal or mildly increased ADC relative to the homologous tract in contralateral hemisphere, with abnormal location and/or direction resulting from bulk mass displacement.

Pattern III (edematous): Characterized by decreased FA and increased ADC. The tract appeared in place or deviated on directional color maps with same colour but fainter due to decreased FA caused by the perilesional edema and the tract was seen passing through the high T2 oedema on conventional study Fig. (3).

Pattern IV (infiltrated and partially disrupted): Characterized by substantially decreased FA and increased ADC. The infiltrated tract is in place or deviated on directional color maps with abnormal hues mostly attributed to disrupted fibers extending into different directions (spurious fibers).

Pattern V (destroyed): It was characterized by isotropic or near-isotropic diffusion, such that the tract or part of it was not identifiable on FA or directional color maps Fig. (4) [7].

\section{Pattern I (not affected):}

White matter fibers are in the correct anatomical location, characterized by normal FA and normal ADC similar to the homologous tract in contralateral hemisphere. This is a rare pattern exclusively found in benign acting tumours. It was seen within 4 cases $(17.4 \%)$ of the benign acting group only and no cases in the malignant acting group Fig. (5).

\section{Pattern II (displacement):}

White matter fibres show normal or mildly decreased FA and normal or mildly increased ADC relative to the homologous tract in contralateral hemisphere, with abnormal location and/or direction resulting from bulk mass displacement. The most common pattern of affection detected in our study is the displacement pattern being detected in both benign and malignant group. Displacement pattern was seen within 19 cases $(82.6 \%)$ of the benign acting group and within 15 cases $(68.2 \%)$ of the malignant acting group Fig. (6).

\section{Pattern III (oedematous):}

The white matter tracts show decreased FA and increased ADC. The tract appeared in place or deviated on directional color maps with same colour but fainter due to decreased FA. Edema pattern was the second most common type of tract involvement. It was seen within 2 cases $(8.7 \%)$ of the benign acting group and within 9 cases $(40.9 \%)$ of the malignant acting group Fig. (7).

\section{Pattern IV (infiltrated and partially disrupted):}

Characterized by substantially decreased FA and increased ADC. The infiltrated tract is in place or deviated on directional color maps with abnormal hues mostly attributed to disrupted fibres extending into different directions. (Spurious fibres). Pattern IV was seen within 2 cases $(8.7 \%)$ of the benign acting group and within 7 cases $(31.2 \%)$ of the malignant acting group Fig. (8).

\section{Pattern V (destroyed):}

The tracts show isotropic or near-isotropic diffusion, such that the tract or part of it was not identifiable on FA or directional color maps. Pattern $\mathrm{V}$ was exclusively seen in malignant acting lesions. It was detected in 3 cases (13.6\%) of the malignant group and no cases in the benign acting group. Fig. (9).

Our study revealed that 20 tumours out of 45 tumours (excluding the tumours with unspecified pathology) were surrounded by different grades of peritumoral vasogenic edema which represents $44 \%$. The benign acting lesions constituted $40 \%$ ( 8 cases out of 20) and the malignant acting lesions constituted $60 \%$ (12 cases out of 20).

We noticed that the edema of benign acting tumours tended to displace (pattern II) the tracts in $75 \%$ rather than infiltrate (pattern III) in $25 \%$. On the other hand, the edema of malignant acting tumours tended to surround and infiltrate the tracts (pattern III) in $83 \%$ of the cases rather than displace them (pattern II) in 17\% only Fig. (10). 

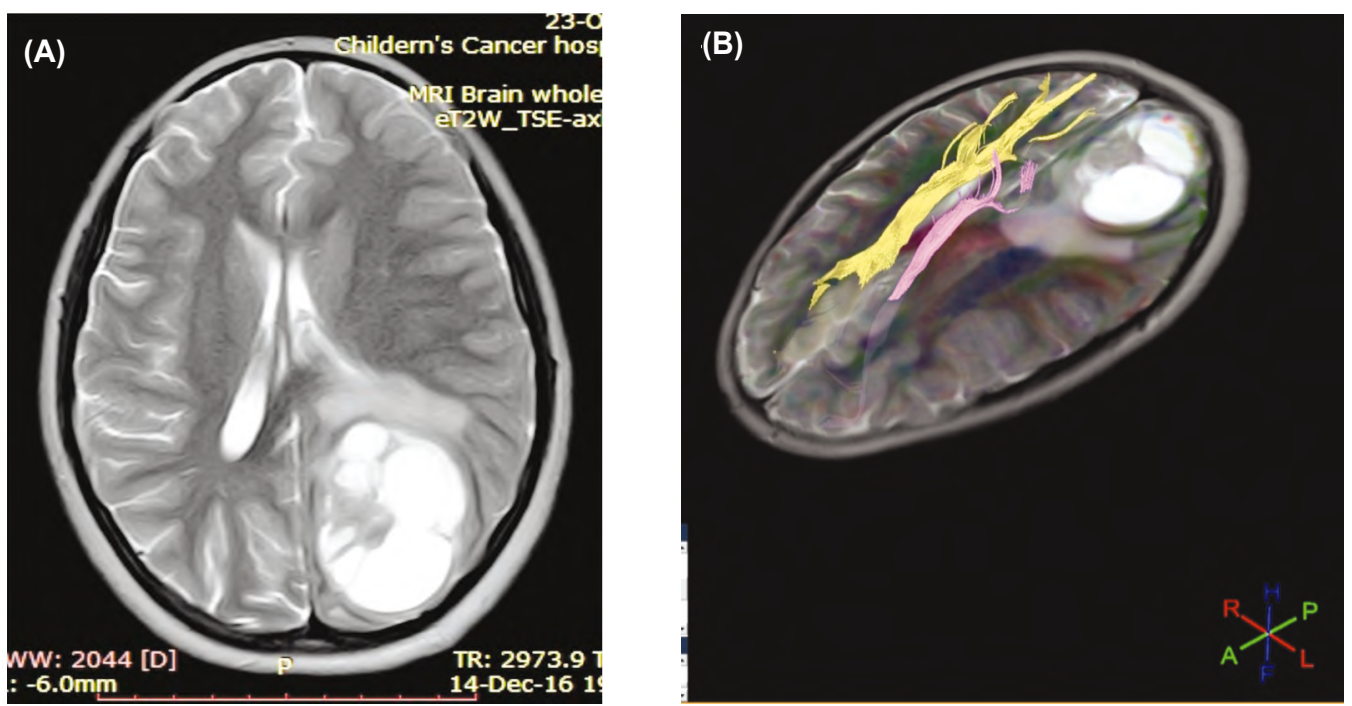

Fig. (3): A 12 years old male patient presented with headache, vomiting and blurring of vision of 3 months duration. Conventional MRI axial T2 image revealed an intraaxial multilocular mostly defined mainly cystic SOL is seen in the left occipital cortical and subcortical region. (A): The lesion is surrounded by grade II vasogenic edema exerting mass effect and mild midline shift. Pre-operative DTI with tractographic reconstruction revealed edema and displacement of the posterior parts of left superior and inferior cingulum (B). This is a case of pathologically proven glioblastoma multiforme grade IV.
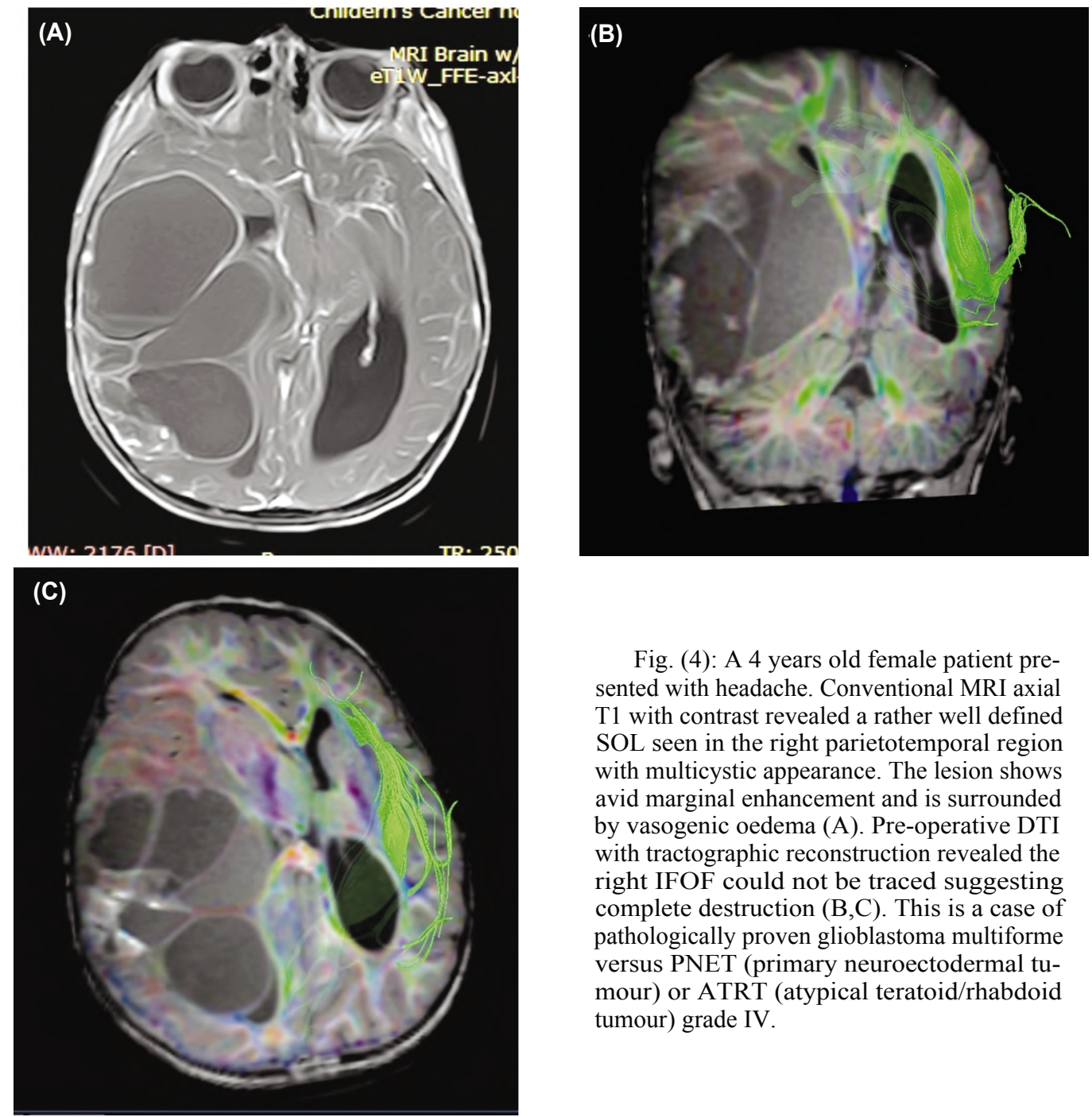

Fig. (4): A 4 years old female patient presented with headache. Conventional MRI axial T1 with contrast revealed a rather well defined SOL seen in the right parietotemporal region with multicystic appearance. The lesion shows avid marginal enhancement and is surrounded by vasogenic oedema (A). Pre-operative DTI with tractographic reconstruction revealed the right IFOF could not be traced suggesting complete destruction $(\mathrm{B}, \mathrm{C})$. This is a case of pathologically proven glioblastoma multiforme versus PNET (primary neuroectodermal tumour) or ATRT (atypical teratoid/rhabdoid tumour) grade IV. 


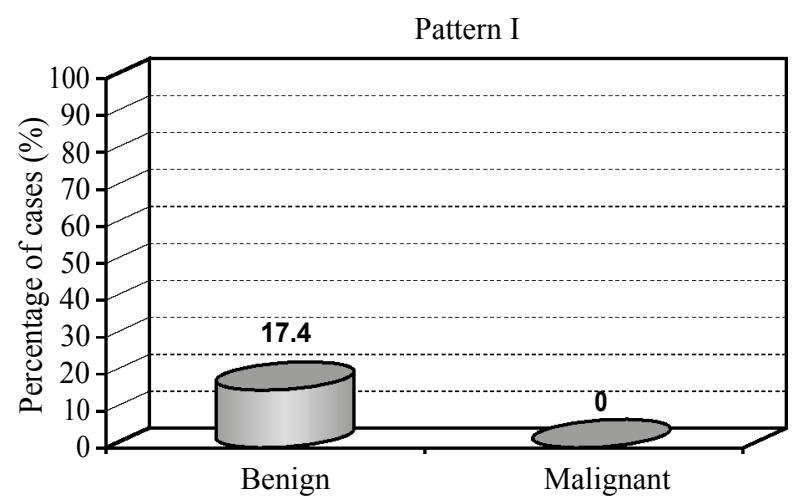

Fig. (5): Pattern I in benign and malignant acting tumours.

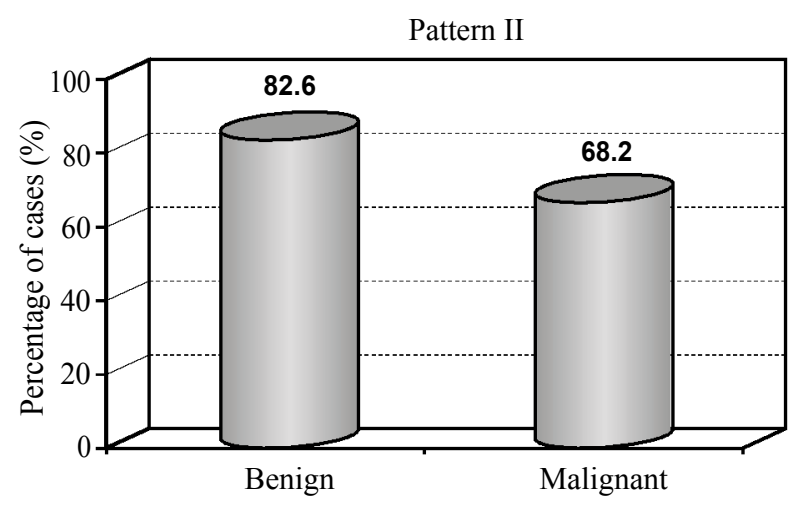

Fig. (6): Pattern II in malignant and benign tumors.

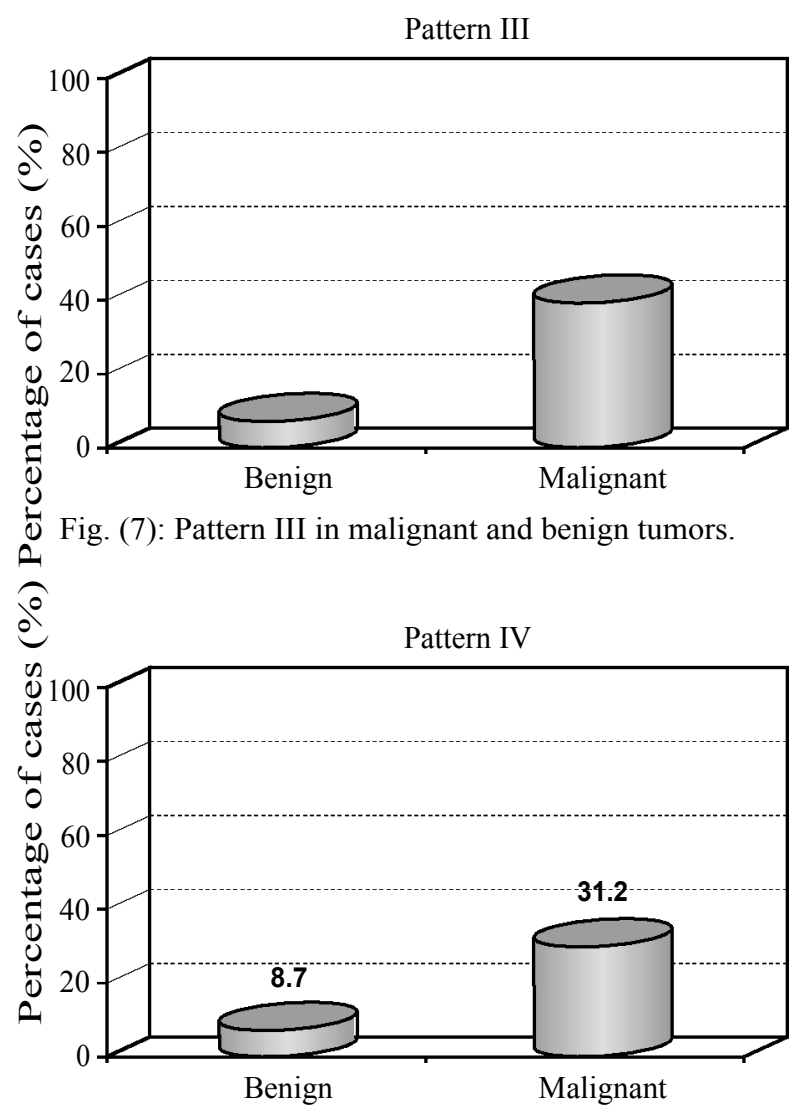

Fig. (8): Pattern IV in malignant and benign tumours.

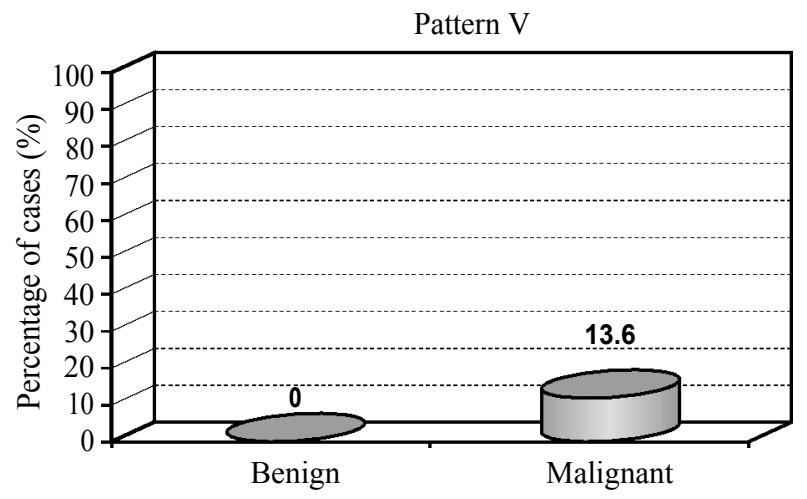

Fig. (9): Pattern V (found in malignant acting tumours exclusively).

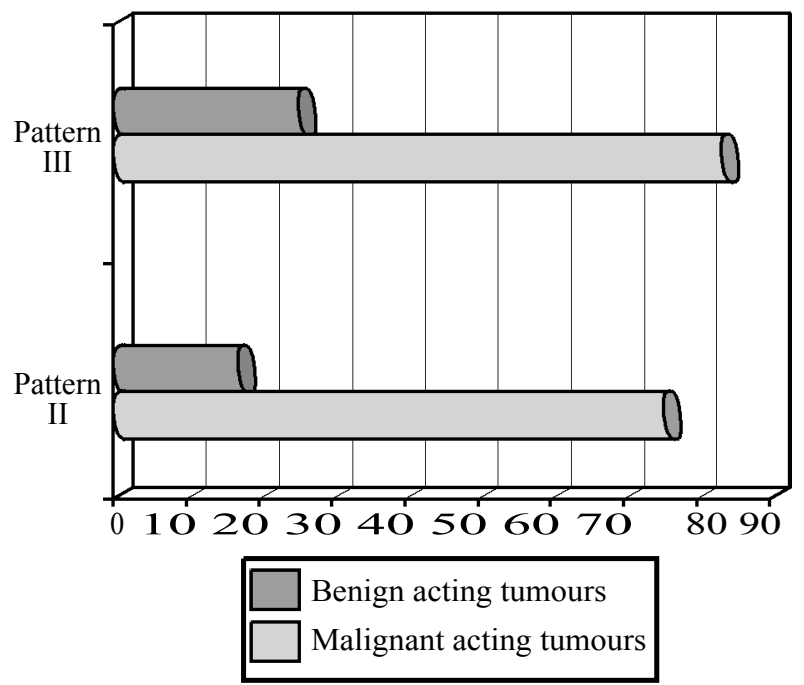

Fig. (10): Behaviour of edema surrounded tumours

\section{Discussion}

Neurosurgery for brain tumors is a trade-off between maximum surgical resection on the one hand and maximum sparing of functions on the other hand. Gross total resection of the tumor reduces the risk of relapse and allow subsequent radiotherapy or chemotherapy to be more effective.

On the other hand, sparing functionally relevant zones and therefore, preservation of motor, visual, or language functions significantly improves the quality of life of these patients.

DTI is a significant advancement in the field of diagnostic imaging. It is, in fact, the only method capable of displaying cerebral WM tracts in vivo $[8]$.

DTI Tractography is one of the methods that can ensure achieving this goal.

Detailed information on the relationship between the effect of the expanding mass on white matter tracts is one of the important facts to be 
taken into account in planning the treatment of patients with eloquent areas brain tumors [9]

Our study was conducted on fifty cases of which 26 patients $(52 \%)$ were males and $13(48 \%)$ were females. The mean age was 7 . Our study included different lesions of the brain, most common diagnosis were gliomas with their different grades.

We further classified the tumors encountered in the study into two main groups, benign acting and malignant acting with the former including grade I and grade II lesions and the later including grade III and grade IV lesions.

In our study, 36 cases (72\%) had supratentorial lesions and in most of these cases the tumor was isolated to one hemisphere. 14 cases $(28 \%)$ had infratentorial posterior fossa tumours mostly located around the 4 th ventricle. In these cases, white matter tract involvement occurred mostly on both sides of the brain.

The most common pattern of affection detected was pattern II (displaced tract) detected in $72 \%$ of all cases. It was seen within $(82.6 \%)$ of the benign acting group and within $(68.2 \%)$ of the malignant acting group. Pattern I (tract not affected) was detected in $12 \%$ of all cases all confined to the benign acting group lesions representing 17\% of them. Pattern III (edematous tract) was detected in $22 \%$ of all cases. It was seen within $(8.7 \%)$ of the benign acting group and within (40.9\%) of the malignant acting group.

Pattern IV (infiltrated, partially disrupted tract) was detected in $26 \%$ of all cases. It was seen within $(8.7 \%)$ of the benign acting group and within $(31.2 \%)$ of the malignant acting group. Pattern V (destroyed tract) was detected in 6\% of all cases. It was exclusively seen within the malignant acting group representing $13.6 \%$ of them. We frequently encountered combined patterns of affection in a large number of cases.

Our study revealed that $44 \%$ of the tumours examined were surrounded by different grades of peritumoral vasogenic edema. The benign acting lesions constituted $40 \%$ of them and the malignant acting lesions constituted $60 \%$ of them.

We noticed that the edema of benign acting tumours tended to displace the tracts (pattern II) in $75 \%$ rather than infiltrate them (pattern III) in $25 \%$. On the other hand, the edema of malignant acting tumours tended to surround and infiltrate the tracts (pattern III) in $83 \%$ of the cases rather than displace them (pattern II) in $17 \%$ only.
It is important to conduct further studies to validate the used classification. This can be achieved by performing a post-operative DTI study for all patients and by correlation with pre and postoperative clinical data (patient's clinical complaint).

Our study mostly agreed with the study done by Field AS et al., 2004. Their study included 13 adult brain tumours which were classified into benign and malignant according to the WHO grading system similar to our study. They identified displacement and edema patterns in both benign and malignant tumors as we did and destruction of tract was limited to malignant tumors as our study also showed. Infiltration and partial disruption of tracts were seen exclusively in malignant lesions, whereas we also identified it in a few benign acting lesions.

The most recent similar study that was also conducted on adult brain tumours was done by Zhukov VY et al., 2016, which partially agreed with our study. They included 23 patients with different brain tumour pathologies which were also classified into benign and malignant according to the WHO grading system similar to our study. They identified infiltration and partial disruption in $20 \%$ of patients with benign acting tumours compared to $8.7 \%$ in our study. It was identified in $42.1 \%$ of patients with malignant acting lesions compared to $31.2 \%$ in our study. It is obvious that this pattern is much more prevalent among the malignant acting group. The displacement pattern was found in the study Zhukov VY et al., 2016 equally present in both groups whereas we noticed a mild increase among the benign lesions.

Our study also partially agreed with the study done by Gomaa and Abd El-Zaher 2012, with prevalence of displacement among the benign acting group and disruption among the malignant acting group.

Displacement pattern was seen within $90.9 \%$ of the benign acting group compared to $82.6 \%$ in our study and within $57.1 \%$ of the malignant acting group compared to $68.2 \%$ in our study. The disruption pattern is seen within $57.1 \%$ within the malignant acting group compared to $44.8 \%$ in our study (pattern IV and V together) and within (9.1\%) of the benign acting group compared to $8.7 \%$ in our study.

Gomaa and Abd El-Zaher 2012 found no significant statistical difference between the two groups in the edema pattern while our results showed significant increase of this pattern in the 
malignant group ( $40.9 \%$ compared to $8.7 \%$ in the benign group).

\section{Conclusion:}

The pathological grade of a paediatric tumour is directly related to the severity of affection of nearby white matter tracts whereas benign acting tumours tend to displace the tracts while more aggressive lesions tend to infiltrate and destroy the tracts.

\section{References}

1- GONZÁLEZ-DARDER J.M., GONZÁLEZ-LÓPEZ P., TALAMANTES F., QUILIS V., CORTÉS V., GARCÍAMARCH G. and ROLDÁN P.: Multimodal navigation in the functional microsurgical resection of intrinsic brain tumors located in eloquent motor areas: Role of tractography. Neurosurg Focus. Feb., 28 (2), 2010.

2- YAMADA K., SAKAI K., AKAZAWA K., YUEN S. and NISHIMURA T.: MR tractography: A review of its clinical applications. Magn. Reson. Med. Sci., 8 (4): 165-74, 2009.

3- SPALICE A., NICITA F., PAPETTI L., URSITTI F., Di BIASI C., PARISI P., RUGGIERI M. and IANNETTI P.: Usefulness of diffusion tensor imaging and fiber tractography in neurological and neurosurgical pediatric diseases. Childs Nerv. Syst., 26 (8): 995-1002, 2010.
4- DIMOU S., BATTISTI R.A., HERMENS D.F. and LAGOPOULOS J.: A systematic review of functional magnetic resonance imaging and diffusion tensor imaging modalities used in presurgical planning of brain tumour resection. Neurosurg. Rev., 36 (2): 205-14, 2013.

5- GAETZ W., SCANTLEBURY N., WIDJAJA E., RUTKA J., BOUFFET E., ROCKEL C., DOCKSTADER C. and MABBOTT D.: Mapping of the cortical spinal tracts using magnetoencephalography and diffusion tensor tractography in pediatric brain tumor patients. Childs Nerv Syst. 26 (11): 1639-45, 2010.

6- LOUIS D.N., PERRY A., REIFENBERGER G., VON DEIMLING A., FIGARELLA-BRANGER D., CAVENEE W.K., OHGAKI H., WIESTLER O.D., KLEIHUES P. and ELLISON D.W.: The 2016 World Health Organization Classification of Tumors of the Central Nervous System: a summary. Acta. Neuropathol., 131 (6): 803-20, 2016.

7- BIANEK-BODZAK A., PIASZCZYK M., BIEGANSKI T. and ZAKRZEWSKI K.: Diffusion tensor imaging of white matter tracts in pediatric patients with cerebral neoplasm. Poster No.: C-2032 Congress: ECR Lodz/PL Doi: 10.1594/ecr2014/C-2032, 2014

8- DUBEY A., KATARIA R. and SINHA V.D.: Role of Diffusion Tensor Imaging in Brain Tumor Surgery. Asian. J. Neurosurg., 13 (2): 302-6. Doi:10.4103/ajns. AJNS_ 226-16, 2018, 2018.

9- ILIESCU B., NEGRU D. and POEATA I.: MR tractography for pre-operative planning in patients with cerebral tumors in eloquent areas. Romanian Neurosurgery, 17: 413-20, 2010 


\section{تقيييم العلاقة بين نوع تأثير الألياف العصبية والنمط الباثولوجى

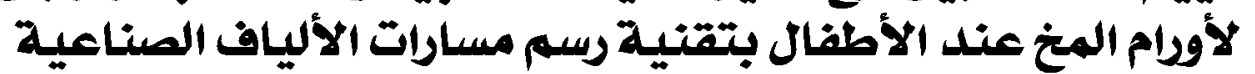
(MR Diffusion Tensor Imaging and Fiber Tractography)

إن الهدف من العلاج الجراحى لآقدام المخ هـ تحقيق أقصى قدر من إستئصال الهدم مع التقليل من العجز العصبى الناتج عن الأضرار

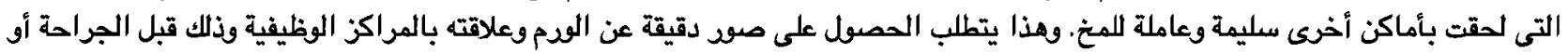

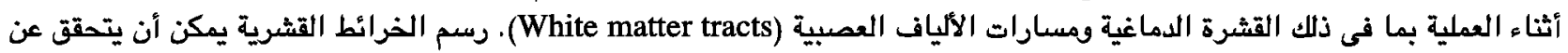

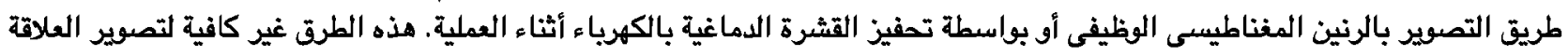

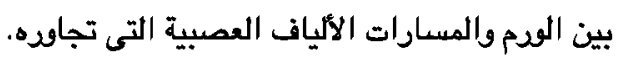

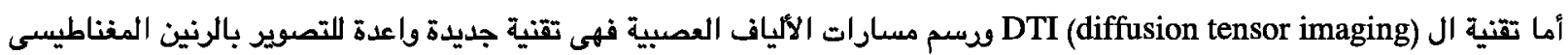
وهى مناسبة بشكل فريد لهذا الدود وأيضاً لها قيمة كبيرة فى توجيه الإجراء الجراحى الفعلى.

تم دراسة حالات تتكون من + ه مريض من الأطفال (الفئة العمرية 1-7 (اسنة) والتى أجريت فى مستشفى السرطان قسم التصوير الطبى

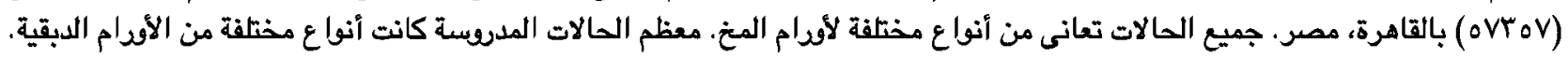

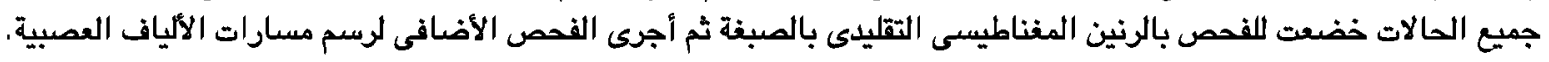
ومن المعرف أن التغيير الذى يحدث لمسارات الألياف العصبية (WM tracts) فى محيط الورام الدماغية قد يؤثر على قياس التباين

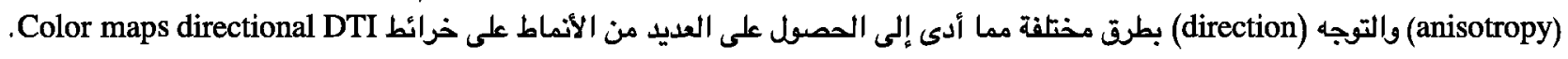
النمط الاكثر ثيوعاً فى دراستنا هو نمط التهجير فى كل من مجموعة الأودام ذو السلوك الحميلى والخبيث ولكن مع أنتشار نمط التهجير

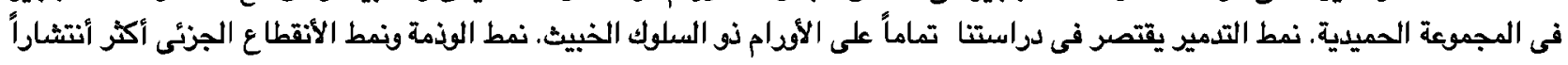
في الأودام ذو السلوك الخبيث.

واجها العديد من القيود والمزالق المتعلقة بتقنية رسم مسارات الألياف العصبية ولكن بالرغم من هذا فأنتا مقتنعقن أنها الطريقة الوحدة

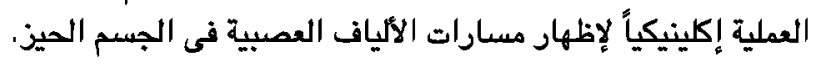

